\title{
Laser-Bonding in High Power Electronics
}

\author{
Influencing the Connection Quality of Copper-Aluminum Welds \\ by a Lateral Beam Displacement and Laser Power Modulations
}

\author{
Michael SCHMIDT ${ }^{* 1}$ and Markus WEIGL ${ }^{* 2}$ \\ *1 Chair of Photonic Technologies, University of Erlangen-Nueremberg, Paul-Gordan-Str. 3, 91052 Erlangen, Germany \\ *2 Bayerisches Laserzentrum, Konrad-Zuse-Str. 2-6, 91052 Erlangen, Germany
}

In the field of high power electronics a trend towards higher thermal loadings, a rising power density and also the need for enhanced dynamic strengths can be seen. These requirements make great demands on the joining technologies, which is why soldering and brazing processes are cumulatively replaced by welding applications. By means of welding it is possible to achieve connections based on metal-joints, featuring a high operating temperature and an excellent electric conductivity. In order to realize short processing times with a concentrated energy input and a high degree of automation, laser systems are well-adapted to meet these challenges. The present article deals with methods and possibilities to increase the mechanical and electrical characteristics of laser-welded copper-aluminum connections. Upon other terms, the influence of a lateral laser-beam displacement towards the aluminum base material and the effects of a pulse modulation within a single laser pulse are discussed. For example, a lateral beam displacement leads to a shifting of the maximum thermal contraction at the end of the laser pulse into the aluminum. Due to the lower yield strength and the higher ductility of pure aluminum in contrast to pure copper, the maximum residual stresses can be reduced by plastic deformation.

DOI:10.2961/jlmn.2010.03.0012

Keywords: laser, bonding, copper, aluminum, ductility

\section{Introduction}

In view of permanent increasing challenges for electronic joints, such as higher thermal loads a rising power density, a cumulative replacement of brazing processes by welding application can be seen. Welded connections feature high operating temperatures as well as an excellent electric conductivity and are therefore adapted to meet the upcoming challenges. Thereby more and more so called tailored constructions are established in order to optimize the total system by connecting the respectively most suitable materials.

Table 1 Selected properties of copper and aluminum

\begin{tabular}{|c|c|c|}
\hline property & copper & aluminum \\
\hline crystal structure & $\begin{array}{l}\text { face-centered } \\
\text { cubic }\end{array}$ & $\begin{array}{l}\text { face-centered } \\
\text { cubic }\end{array}$ \\
\hline density $\left[\mathrm{g} / \mathrm{cm}^{3}\right]$ & 8.9 & 2.7 \\
\hline $\begin{array}{l}\text { electrical conductivity } \\
{\left[10^{6} * \mathrm{~S} / \mathrm{m}\right]}\end{array}$ & 58 & 38 \\
\hline $\begin{array}{l}\text { thermal conductivity } \\
{\left[\mathrm{W} / \mathrm{m}^{*} \mathrm{~K}\right]}\end{array}$ & 401 & 237 \\
\hline $\begin{array}{l}\text { thermal expansion coef- } \\
\text { ficient }\left[10^{-6} / \mathrm{K}\right]\end{array}$ & 24 & 17 \\
\hline melting point $\left[{ }^{\circ} \mathrm{C}\right]$ & 1084 & 660 \\
\hline boiling point $\left[{ }^{\circ} \mathrm{C}\right]$ & 2567 & 2467 \\
\hline
\end{tabular}

For application in high power electronics, a material connection of particular interest is the combination of copper and aluminum. While copper features an excellent electrical and thermal conductivity, its comparatively high market price leads to rise in cost for electronic constructions. Further more, the high density of copper, $8.9 \mathrm{~g} / \mathrm{cm}^{3}$ according table 1 , restricts the need for a lightweight design. Therefore it is intended to replace copper by an alternative material, which features similar electric properties as copper at a reduced market price and a lower specific density. Particularly aluminum offers characteristics similar to copper, at only one third of copper's density, see table 1 .

However joining of copper and aluminum by means of metallic continuity causes miscellaneous difficulties. Besides worse absorption factors of less than 5\% for the typical industrial laser wavelengths (1064 nm, $10600 \mathrm{~nm})$, copper and aluminum form a lot of intermetallic phases. Most of them feature high hardness values coming along with a distinctive brittleness. Already established studies [1] demonstrate the advantageous effect of silver foils and coatings as further alloying element in comparison to pure copper / aluminum welds. Another progression of the achievable tensile strengths can be reached by a systematic enrichment of the aluminum percentage in the welding spot. For example this can be done by a lateral displacement of the laser beam and the fusion gap towards the aluminum component, or an appropriate irradiation angle [2]. Further more, a lateral beam displacement towards the aluminum influences the formation of crack directly after the welding process.

In this context, the present article discusses the possible causes for the reduction of the crack formation by using a lateral beam displacement. In addition, the effects of a laser power modulation on the mixing process during micro welding of copper with aluminum are investigated. By means of adapted modulation factors and frequencies the intensity of intermixture of all elements concerned shall be varied. Thereby a local formation of brittle phases shall be minimized, targeting an increasing ductility of the dissimilar connections. 


\section{Basics of the experimental trials}

\subsection{Sample geometry and laser systems}

For the experimental studies sheet metal samples made of E-Cu58 and A199.9 are used. In lap joints of such specimen with $1.2 \mathrm{~mm}$ thickness and a silver interlayer of $50 \mu \mathrm{m}$ [1], always three spots per side are welded along the lateral surfaces, see figure 1. Three spots per side were chosen in order to get an averaging effect over the sample itself and a symmetrical load distribution during the tensile tests.

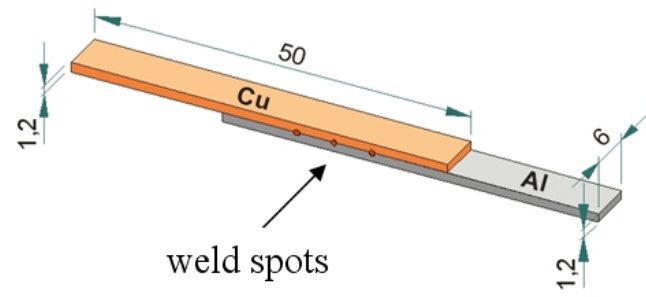

Figure 1 Sample geometry

Laser-spot welding is typically performed by the use of pulsed laser systems, which allow high peak power and short pulse duration. The relevant data of the Nd:YAGlaser used for the experimental trials is shown in table 2.

Table 2 Relevant data of the pulsed laser system

\begin{tabular}{ll}
\hline producer & Lasag \\
type & SLS 200 CL60 \\
wavelength $[\mathrm{nm}]$ & 1.064 \\
peak power $[\mathrm{kW}]$ & 7 \\
maximum pulse duration $[\mathrm{ms}]$ & 100 \\
spot diameter $[\mu \mathrm{m}]$ & 400 (measured) \\
beam profile & gaussian
\end{tabular}

\section{Results of the analytical and experimental research}

\subsection{Lateral beam displacement}

The lateral beam displacement describes a local shifting of the laser spot from the joining gap towards one of the base materials. Already established studies [4-10] demonstrate that at $\mathrm{Cu}-\mathrm{Al}$ laser welds a lateral beam displacement towards the aluminum base material leads to higher tensile strengths during tensile tests. In this way the absorption of the laser wavelength of $1.064 \mathrm{~nm}$ can be raised and higher reproducibility is reached. In addition, a beam displacement towards aluminum increases the percentage of aluminum in the weld spot. According to binary $\mathrm{Cu}-\mathrm{Al}$ phase diagrams [3], a higher aluminum percentage is advantageous for a reduction of the intermetallic phases and therewith the micro-hardness. In [5] it is also mentioned, that a lateral beam displacement in the dimension of half the laser spot diameter leads to the best connection qualities. As the laser system used features a spot diameter of
$400 \mu \mathrm{m}$, see table 2, a lateral beam displacement of $200 \mu \mathrm{m}$ towards the aluminum base material is chosen.

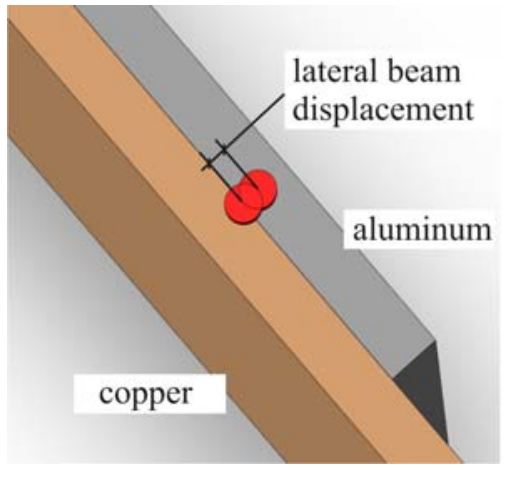

Figure 2 Definition of the lateral beam displacement

In order to clarify the positive effect of the lateral beam displacement towards aluminum on the resulting tensile strengths and the electrical conductivity, numerical simulations with the software Abaqus are performed. Corresponding to the experimental trials in [4], a laser power of $4.400 \mathrm{~W}$ and a pulse duration of $9 \mathrm{~ms}$ are assumed. The analytical model features an elastic-plastic behavior, a refinement of the mesh in the contact area and a uses the symmetry of the weld spot, see figure 3

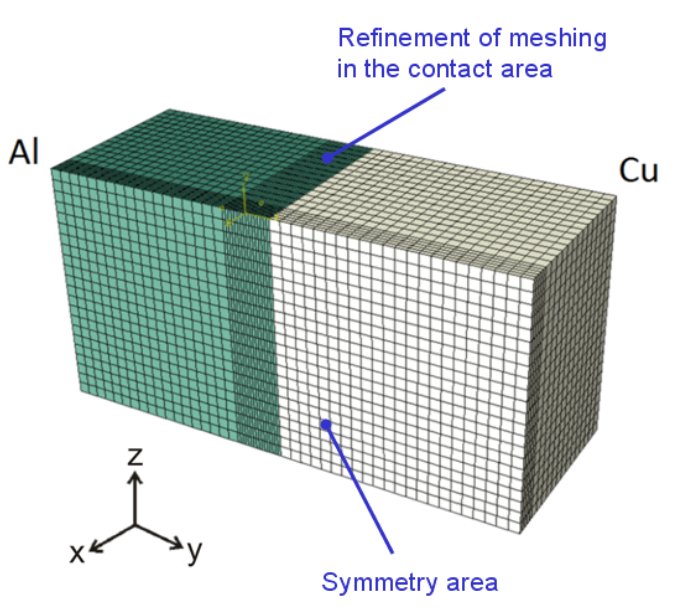

Figure 3 Meshed geometry for the numerical simulation

Figure 4 displays a temporal sequence of simulated states of the inner stresses during welding a copperaluminum connection with a beam displacement of $0.2 \mathrm{~mm}$ to the aluminum. $3.5 \mathrm{~ms}$ after starting the welding process, the keyhole extends to the maximum depth for the first time. At this point of time the weld zone is immensely heated and wants to extend, while the ambient material still remains cold and inhibits a thermal expansion. Therefore compression stresses (negative values in figure 4) up to $120 \mathrm{MPa}$ are reached. Regarding technical pure copper and aluminum these stresses are higher than the yield strength, so that in reality a plastic occurs. At $9 \mathrm{~ms}$, when the laser power is stopped, the formerly compressed area starts cooling down and therefore wants to shrink. As a consequence, the algebraic sign of the internal stresses changes - imply- 
ing a conversion of compression into tensile stresses, see figure 4.

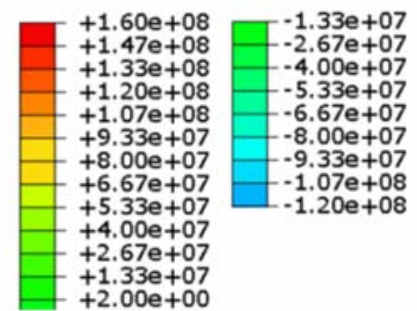

Internal stresses in $\mathrm{Pa}$ (y-direction)

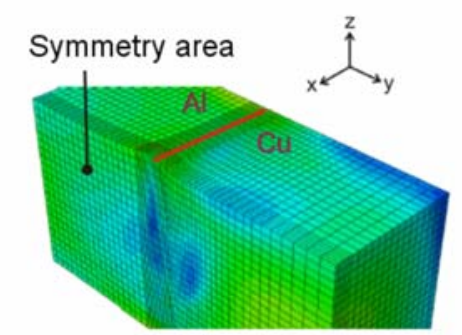

Time: $3,5 \mathrm{~ms}$ (during welding)

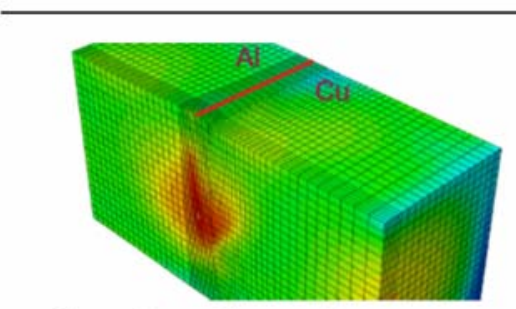

Time: $9 \mathrm{~ms}$ (laser off)

Figure 4 Internal stresses during the welding process with a lateral beam displacement of $0.2 \mathrm{~mm}(\mathrm{Al})$

After a time of $60 \mathrm{sec}$, in the simulation a complete cooling down to ambient temperature is reached and the remaining internal stresses can be seen. At welds without a lateral beam displacement, see figure 5, the maximum remaining stresses amounts to $+120 \mathrm{MPa}$. Beyond that, the area of the maximum stresses within the connection can be found at the transmission zone between weld spot and heat affected zone at the copper base material. According to [5] this is exactly the zone, where the intermetallic phases with the highest hardness can be expected. In contrast to that, at welds with a lateral beam displacement of $0.2 \mathrm{~mm}$ towards aluminum, the maximum residual stresses show a dimension of $+90 \mathrm{MPa}$, which is $25 \%$ less compared with a centered irradiation. Further more, no significant peaks of the stress distribution can be detected at the transmission zone between weld spot and heat affected zone at the copper side, see figure 5. Consequently, the preload of welds with beam displacement is considerably less and for mechanical purposes shows a favorable distribution.

In reality, the minor yield strength of aluminum combined with a higher ductility in contrast to copper, allows a reduction of the residual tensile stresses by an enlarged plastic deformation of the aluminum. Hence the remaining reserves considering mechanical loads are higher and samples welded with a beam displacement towards aluminum reach higher tensile strengths and breaking elongations. Additionally the use of a lateral beam displacement towards the aluminum base material also effectuates a more harmonic distribution of stresses without peaks at the critical transition area at the weld seam nearby the copper base material.
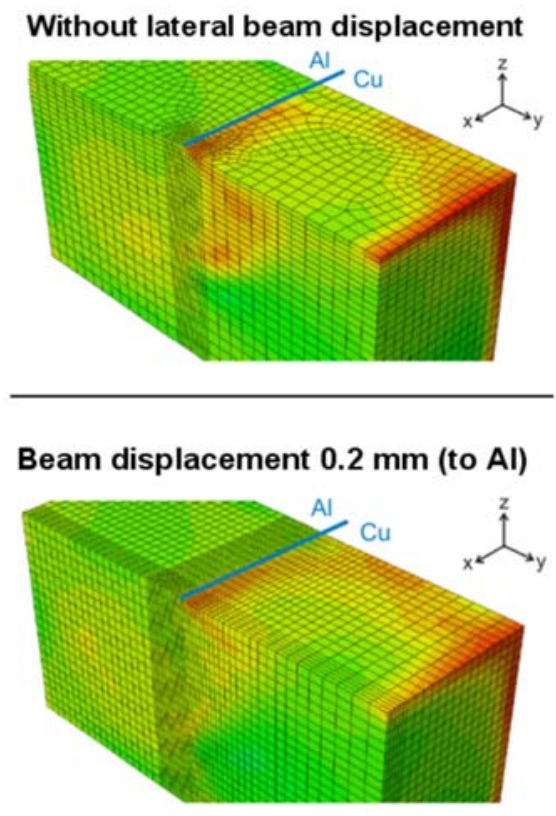

Figure 5 Comparison of the remaining internal stresses at welds without / with a lateral beam displacement of $0.2 \mathrm{~mm}$ to aluminum after cooling down (legend acc. figure 4)

In this manner also the risk of a crack-formation during the welding process can be minimized. Micro-cracks represent a non-connected area for both, a mechanical load and the electrical conduction. Therefore for samples welded with a lateral beam displacement, also a higher long-term stability of the electrical conductivity may be expected. Corresponding experimental tests will to be performed in near future.

Summarized up, a lateral beam displacement in the dimension of half the spot diameter can be recommended for laser spot welds at $\mathrm{Cu} / \mathrm{Al}$ connections. Besides the already demonstrate increase of the absorption rate for the Nd:YAG wavelength and an enhancement of the metallurgy, a reduction of the residual stresses caused by the joining process can be reached.

\subsection{Laser power modulation}

In order to reach a higher mixing ratio of the elements involved in the welding process, the laser power shall be modulated within the laser pulse. The desirable element distribution of copper, aluminum and optionally applied filler materials, such as silver, would be a harmonic distribution without critical ratios according the binary phase diagram [3].

Basis for the modulation experiments is an optimized pulse shape with three segments in principal: preheating, welding and cooling. During the preheating the sample is 
heated up, wherewith a better absorption of the laser radiation is attended. Subsequent the welding process starts, a melting of the materials starts and a metallic continuity results. In the last segment the laser power is reduced in such a way that cracks caused by too high rates of cooling as well as weld puddles on the surface shall be minimized. Considering a representative pulse shape with a total duration of $9 \mathrm{~ms}$, the preheating stage in phase (1) lasts about $0.9 \mathrm{~ms}$, during which $15 \%$ of the maximum laser power is used, see Fig. 6. That followed the peak power is set to $100 \%$ for a period of about $2.5 \mathrm{~ms}$ in phase (2) and a sinusoidal modulation with different frequencies and modulation depths is implemented. In this phase (2) the welding process takes actually place and a metallic connection is produced. Based on this level the laser power is reduced in a linear way down to $0 \%$ at $9 \mathrm{~ms}$, see figure 6 .

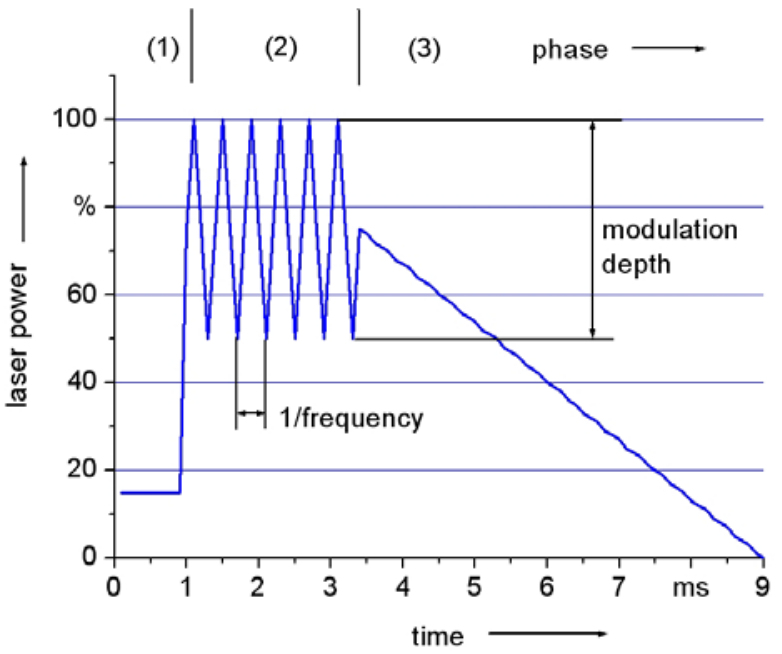

Figure 6 Pulse shape for the power modulations

After measurements and analysis of reflected process emissions the maximum modulation depth is set to $50 \%$ at a maximum frequency of $2.000 \mathrm{~Hz}$. Between no laser power modulation and the mentioned limits, the following modulation depths and frequencies are used for the experiments:

o Modulation depths: $0 \%, 2 \%, 5 \%, 10 \%, 25 \%$ and $50 \%$

o Frequencies: $0 \mathrm{~Hz}, 350 \mathrm{~Hz}, 850 \mathrm{~Hz}, 1.300 \mathrm{~Hz}$ and $2.000 \mathrm{~Hz}$

The laser peak power, i. e. the $100 \%$ level in figure 6 , is set to $6.25 \mathrm{~kW}$ in order to reach an extensive cross section of the connected material. With each combination of modulation depth and frequency 9 samples are welded, so that a characterization just after the joining process, as well as after static and dynamic long-term tests, is possible.

During the tensile tests of as-welded components a significant gain in tensile strengths can be detected for samples produced with modulation depths of $2 \%$ and $5 \%$ at frequencies of less than $850 \mathrm{~Hz}$, see figure 7. Reaching almost $1.100 \mathrm{~N}$, about 20\% higher strength values can be reached in contrast to samples welded without a sinusoidal modulation ("REF" in figure 7). On the other hand modulation depths higher than $5 \%$ and frequencies above $850 \mathrm{~Hz}$ only achieve tensile strengths of $\leq 855 \mathrm{~N}$, which is less than the level of non-modulated reference specimen, welded with the same average power.

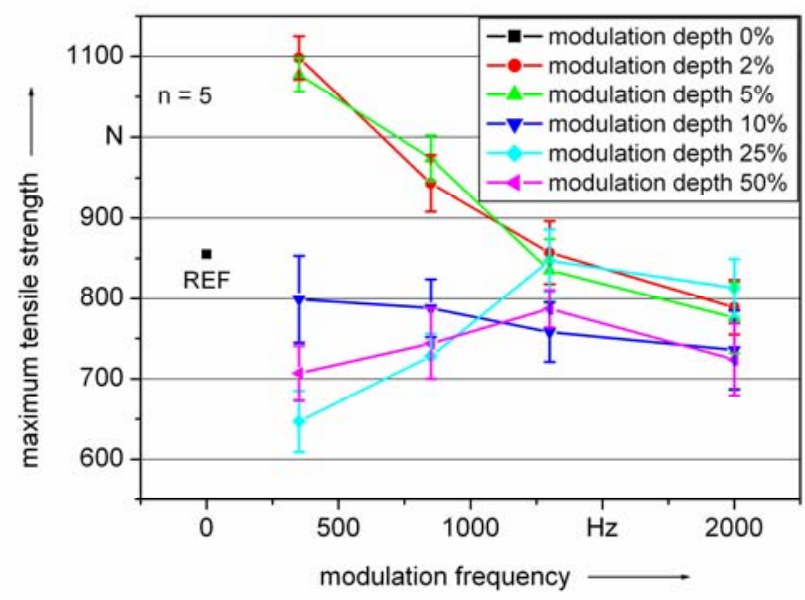

Figure 7 Tensile tests of samples, welded with different modulation depths and frequencies

For a better understanding of this effect metallographic specimens of all samples are taken and etched with $\mathrm{FeCl}_{3}$. By this etching solution especially the copper parts in the fusion zone corrode and appear darker in the subsequent micrograph. Contrariwise neither the silver interlayer nor the highly concentrated aluminum parts are affected and appear brighter in consequence.

By comparing samples produced with the parameter set of $5 \%$ modulation depth at $850 \mathrm{~Hz}$ and such one welded with $50 \%$ at $2.000 \mathrm{~Hz}$ a different mixture of the elements can be recognized in the weld spots, see figure 8 . Lower modulation depths, such as $2 \%$ to $5 \%$, lead in conjunction with frequencies of $0 \mathrm{~Hz}$ to $850 \mathrm{~Hz}$ to a more linear style of intermixture. This can be seen by the aluminum and especially the silver flow marks, which show a stretched expansion from one base material towards the other. Tensile loads in direction of these flow marks can be sustained very well by such a structure, because of the continuous connections of both base materials by throughout element layers, see left side of figure 8 . On the other hand, higher modulation depths, such as $25 \%$ and $50 \%$, at frequencies between $1.300 \mathrm{~Hz}$ and $2.000 \mathrm{~Hz}$ cause a more insular shaped microstructure. Aluminum and silver form spotted zones all over the welded zone without a distinctive coherence, see right side of figure 8 . Hence lateral forces in a tensile test can not be transferred over the spot zone in such a direct way as the more linear structure reached with lower modulation parameters allows.

Another important observation can be seen by the way of more detailed analysis of the phase changes from the fusion zone towards the base materials. While the mixture of all elements concerned features certain characteristics in the core area of the spot, the regions nearby the base substances shows no typical form in direct dependence of the modulation parameters. Known from the binary and ternary phase diagrams of copper, aluminum and silver [3], particularly high copper concentrations lead to an intense formation of intermetallic phases with aluminum. In most cases these phases are distinguished by high hardness values and therewith a remarkable brittleness. 

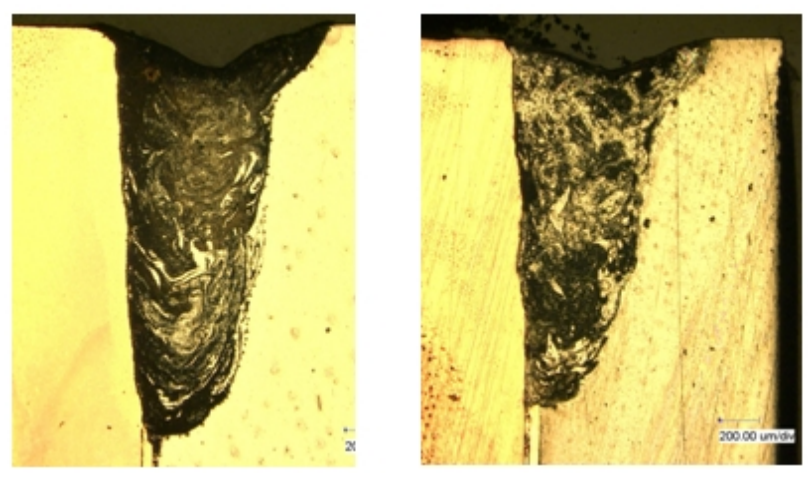

Figure 8 Etched metallographic specimen of samples welded with modulation depth $5 \%$ at $850 \mathrm{~Hz}$ (left) and $50 \%$ at $2.000 \mathrm{~Hz}$ (right)

Since the modulation arrangements cause no direct influence on these brittle zones, especially at the copper side of the weld spot, the considered actions identify no optimization concerning the ductility of the samples. Instead the main percentage of all samples suffers a brittle fracture at the copper side of the connection. As a consequence almost all samples show the same ductility values as the references, which have been welded without modulation and with an identical average power. Up to now no significant increase of the ductility of copper-aluminum welds can be achieved by means of laser power modulations. As a consequence, the appearance of fracture of samples welded with a laser power modulation also shows a high percentage of brittle fracture, see figure 9. In most of the tensile test the position of fracture can be found in the transition are between the weld spot and the heat affected zone of the copper base material.

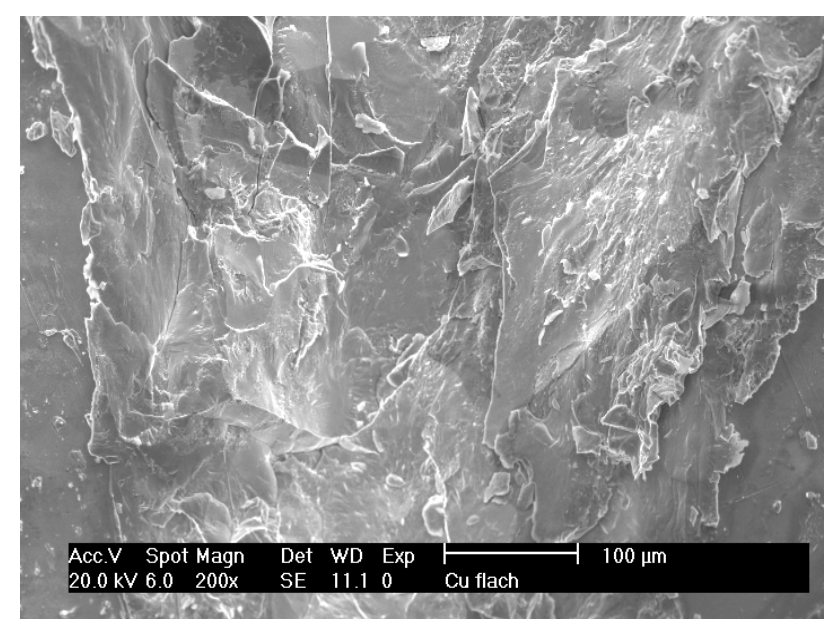

Figure 9 SEM-micrograph of a broken $\mathrm{Cu} / \mathrm{Al}$ sample, welded with a modulation depth of $50 \%$ at a frequency of $2.000 \mathrm{~Hz}$ (magnification 200x)

Additionally performed EDX-analyses approve, that by means of laser power modulations with the parameters mentioned above no significant influence on the ductility of the connection can be reached. The weld seam at the copper side of the $\mathrm{Cu} / \mathrm{Al}$ connection remains the metallurgical weak-point. In order to clarify, whether higher modulation frequencies enhance the intermixture of the participating elements in the weld zone, further trials with higher frequencies are planned.

\section{Conclusions and outlook}

By means of a lateral laser beam displacement in the dimension of half the spot diameter towards aluminum, higher absorption rates for the Nd:YAG laser irradiation and an advantageous microstructure at $\mathrm{Cu} / \mathrm{Al}$ connections can be reached. In addition it can be evidenced by numerical simulations, that a beam displacement towards aluminum effectuated a reduction of the maximum residual tensile stresses. This fact is caused by shifting the area of the maximum tensile stresses during the cooling down phase in the welding process to the aluminum. As technical pure aluminum features a minor yield strength coming along with a higher ductility in contrast to copper, the peak stresses can be reduced by plastic deformation. Further more, welds with a beam displacement lead to a more harmonic distribution of the stresses inside the weld spot, whereas welds with a centered irradiation exhibit peaks of the tensile stresses in the transition zone between weld spot and heat affected zone of the copper.

Laser power modulations based on sinusoidal pulse segments during spot welds of copper-aluminum samples lead to varying microstructures caused by modified mixing effects. In particular modulation depths of $2 \%$ and $5 \%$ at frequencies of $350 \mathrm{~Hz}$ and $850 \mathrm{~Hz}$ cause higher tensile strengths of about $20 \%$ in relation to reference samples, welded without modulations at the same average power. The more linear shaped mixture of elements in connections welded with the implied parameters is able to transfer the internal stresses very well. As a consequence higher strength values are resulting. On the other hand the ductility of such connections is mainly determined by the formation of brittle phases nearby the phase changes from weld spot to base material. All modulation parameters considered don't affect these critical zones, as the mixing processes in those regions of a weld spot differ form the core area. Consequently other possibilities have to be used, in order to influence the formation of brittle phases significantly.

One possibility to completely prevent the interaction of copper and aluminum in the molten state it the use of rollcladded $\mathrm{Cu} / \mathrm{Al}$ adapter pieces. Adapted fittings made from roll-cladded copper-aluminum sheet metal can be used to divide the one dissimilar connection into two similar connections, aluminum-aluminum on the one side and coppercopper on the other side. By doing so, the dissimilar connection is transferred to a standardized process, the rollcladding, and the formation of brittle phases can be minimized. Thus, especially the ductility of copper-aluminum joints is supposed to increase and the contact resistance of the connection reduces. Corresponding experimental tests will be performed in the near future. 


\section{References}

[1] Mys, I.; Schmidt, M.; Esser, G.; Geiger, M.: Method for welding dissimilar metal joining partners, in particular, aluminum-copper connection points. Patent WO 2005/082569 A1, 2005

[2] Mys, I.; Schmidt, M.: Laser micro welding of dissimilar $\mathrm{Cu}-\mathrm{Al}$ materials for electronic contacts. In: Laserbased Micropackaging, Proceedings of SPIE, Vol. 6107, 2006

[3] MSIT world library: Binary and ternary phase diagrams, www.matport.com, 2010

[4] M. Schmidt, M. Weigl, Modulated laser spot welding of dissimilar copper-aluminum connections, Proceedings of 4M/ICOMM conference, pp. 211-214, 2009

[5] M. Schmidt, M. Weigl, Untersuchungen zur gezielten Gefügeeinstellung beim gepulsten LaserstrahlMikroschweißen von Kupfer-AluminiumVerbindungen, DVS Schweißen und Schneiden, 4/2009, pp. 204-208, 2009

[6] K. Klages: Laserstrahl-Mikroschweißen ungleicher Metalle durch Nahtschweißen mit gepulsten Nd:YAGLasern. Dissertation. RWTH Aachen, 2006

[7] Abschlussbericht BMBF Vorhaben Optomat Optische Technologien zur Herstellung mikrotechnischer Produkte aus artungleichen Materialien. Aachen, 2006

[8] Pohle, C.: Schweißen von Werkstoffkombinationen Metallkundliche und fertigungstechnische Grundlagen sowie Ausführungsbeispiele. Fachbuchreihe DVSVerlag, Düsseldorf, 2000

[9] Schoer, H.: Schweißen und Hartlöten von Aluminiumwerkstoffen. DVS-Verlag, Düsseldorf, 2002

[10] Rongshi Xiao Peng Dong, Kai Chen: Laser beam welding of dissimilar materials. ICALEO 2009, Paper 1601 